“ (C) 2018 IEEE. Personal use of this material is permitted. Permission from IEEE must be obtained for all other uses, in any current or future media, including

reprinting/republishing this material for advertising or promotional purposes, creating new collective works, for resale or redistribution to servers or lists, or reuse of any copyrighted component of this work in other works." 


\title{
A Fuzzy Multi-Layer Assessment Method for EFQM
}

\author{
Jay Daniel, Mohsen Naderpour, Member, IEEE, Chin-Teng Lin, Fellow, IEEE
}

\begin{abstract}
Although the European Foundation for Quality Management (EFQM) is one of the best-known business excellence frameworks, its inherent self-assessment approaches have several limitations. A critical review of self-assessment models reveals that most models are ambiguous and limited to precise data. In addition, the impact of expert knowledge on scoring is overly subjective, and most methodologies assume the relationships between variables are linear. This paper presents a new fuzzy multi-layer assessment method that relies on fuzzy inference systems (FISs) to accommodate imprecise data and varying assessor experiences to overcome uncertainty and complexity in the EFQM model. The method was implemented, tested, and verified under real conditions in a regional electricity company. The case was assessed by internal company experts and external assessors from an EFQM business excellence organization, and the model was implemented using Matlab software. When comparing the classical model with the new model, assessors and experts favored outputs from the new model.
\end{abstract}

Index Terms - EFQM, business excellence model, selfassessment, fuzzy inference systems.

\section{INTRODUCTION}

$\mathrm{I}$ $\mathrm{n}$ an increasingly turbulent business environment, many organizations are choosing to adopt different quality management approaches for achieving business excellence and maintaining a sustainable competitive advantage. The majority of these approaches rely on a standard set of assessment criteria to assess, or self-assess, an organization's performance. Some of the better-known quality award frameworks include the European Quality Award (EQA), the American Malcolm Baldrige National Quality Award, and the Japanese Deming Prize [1].

The EFQM is a membership-based non-profit organization that was established in 1988 by 14 representatives of European multinational organizations. Its mission is to drive sustainable excellence in Europe [2-4]. The EFQM model is a framework for organizational self-diagnosis in quality excellence. According to the EFQM, following the sustainable excellence criteria (Figure 1) provides outstanding results with respect to performance, customers, people, and society. These results are achieved through "leadership driving policy and strategy that is delivered through people, partnerships and resources, and processes" [3, 5].

The self-assessment process in the EFQM model aims to

Jay Daniel is with Derby Business School, University of Derby, Kedleston Rd, Derby DE22 1GB, UK (e-mail: J.Daniel@ derby.ac.uk).

Mohsen Naderpour is with the Centre for Artificial Intelligence (CAI), Faculty of Engineering and IT, University of Technology Sydney (UTS), Ultimo, NSW 2007, Australia (e-mail: Mohsen.Naderpour@uts.edu.au). increase motivation for business improvement. Self-assessment is conducted through a systematic, regular, and comprehensive examination of business performance, and the results are interpreted against the standards of the EFQM Business Excellence model. The EFQM model defines self-assessment as the process of enabling a company to clearly identify areas of strength and areas for improvement. Improvement action plans are subsequently implemented and monitored for progress [6]. The EFQM model has introduced several self-assessment approaches, including questionnaires, matrix charts, workshops, proformas, and award simulations. Moreover, these approaches have been studied by numerous researchers in several companies $[2,5,7,8]$.

However, the assessment methods in the EFQM model have several limitations. The quality of the empirical investigation is indeterminate, and the assessors' knowledge and skills with the assessment system cannot be verified as their judgment is qualitative and subjective [9-11]. There is a linear association between the EFQM criteria where, in reality, the relationship between the assessment criteria and the variables is nonlinear $[9,12,13])$. Further, uncertain and imprecise assessment data (linguistic variables) cannot be converted into crisp data, and expert knowledge and experience cannot be seamlessly incorporated into the assessment [9-11].

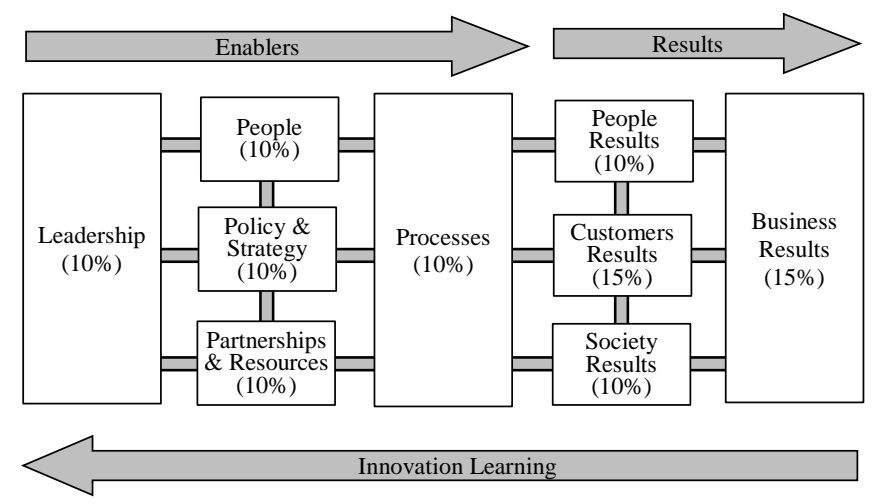

Fig. 1. The EFQM model [2, 5].

The main objective of this research is to develop an intelligent fuzzy assessment method to overcome the current

CT Lin is with the Centre for Artificial Intelligence (CAI), Faculty of Engineering and IT, University of Technology Sydney (UTS), Ultimo, NSW 2007, Australia (e-mail: Chin-Teng.Lin@uts.edu.au). 
limitations in the EFQM model and, in doing so, address some key gaps in the existing literature. The main contribution of this paper is a fuzzy multi-layer assessment method that incorporates assessor knowledge and experience into the assessment process using a network of FISs. The method can be used to analyze linguistic, uncertain, and imprecise data, while promoting linguistic reasoning and aggregating subjective evaluations. The proposed method overcomes the presumed linear relationship among criteria in multi-criteria decision-making (MCDM) methods. Hence, the method captures and characterizes nonlinear relationships. The efficacy of the method is explored through a real-world case study. The results demonstrate satisfactory performance.

The method also has some practical implications. Many companies struggle with intensive resource requirements of a manual self-assessment process. The method presented in this paper has been designed as an integrated and continuous selfassessment activity, where the demands of self-reflection and improvement are partially relegated to automated processes. Further, in the first step of the EFQM, it helps top and/or second-level company managers to identify strengths and areas for improvement.

The rest of this paper is structured as follows. Section 2 reviews the literature related to EFQM and its assessment methods. The proposed model and case study are discussed in Sections 3 and 4. Finally, Sections 5 and 6 present the discussion, conclusion, and directions for future work.

\section{LITERATURE REVIEW}

The literature review begins with a discussion on quality management and business excellence, along with the various models and methods that have been developed to guide practitioners through assessment processes. Then, the basic definition of fuzzy logic and FISs are reviewed.

\section{A. EFQM Model}

In 1991, the EFQM introduced the EQA to acknowledge organizations that demonstrate a strong commitment to business excellence. Organizations in Europe that successfully implement this quality management framework are eligible to receive an EQA endorsement, which is nominally held by the recipient for a year. Applicants need to demonstrate their approach to quality management by substantially fulfilling customer and employee demand. Applying for the EQA has advantages for an organization, including enhancing the focus of a company and its improvement processes, encouraging teamwork, and creating an awareness of the need for quality management. Further advantages of receiving an EQA endorsement include the provision of management improvement services by the EFQM, use of the EQA logo in corporate literature, support from the European Commission and European Organization for Quality, and being listed as one of the most accomplished companies in Europe. There are four award units: independent businesses (either whole companies or parts of companies); cost centers (operational units within a business); public sector organizations; and small-to-mediumsized enterprises (fewer than 250 people) $[2,14,15]$.
The number of organizations applying for the EFQM framework in Europe and globally is growing rapidly, with more than 20,000 organizations currently employing the model to manage improvement activities [16].

\section{B. EFQM Model Criteria}

The nine boxes in the model as shown in Figure 1 outline the criteria used to evaluate a company's growth with respect to excellence. These are defined as follows $[3,5]$ :

- Leadership: Leaders develop and facilitate their company's mission and vision by developing organizational values and systems for continued success. They demonstrate these values through actions and behaviors and, in particular, by maintaining stability during times of change; leaders should be able to steer the direction of their organization by appropriately motivating and guiding staff.

- People: Organizations value staff and create a culture that promotes mutually advantageous achievement of organizational and personal goals. These organizations encourage sound values of justice and impartiality, develop staff capacity, encourage staff commitment, and employ skills and knowledge to benefit the organization.

- Policy and Strategy: Policies, plans, objectives, and processes are developed and implemented to build a strategy that focuses on stakeholders.

- Partnerships and Resources: External partnerships, suppliers, and internal resources are managed according to the policies and strategies set. They also support efficient operational processes.

- Processes: Processes are planned, managed, and enhanced to increase value for customers and other stakeholders.

- Results for People, Customers, and Society: Excellent organizations extensively measure and monitor outcomes that are significant to their customers, people, and society.

- Business Results: The outcomes identified for assessment align with the organization's key policies and strategies.

\section{Self-assessment Methods}

Organizational self-assessment is appropriate for the field of quality management and is acknowledged as a vital stimulus for increasing performance. For this reason, it has become one of the main concepts in business excellence models. Many organizations have implemented models that use selfassessment as a tool to find where they are now, where they need to improve, and, consequently, to make decisions on how to reach those goals $[12,17,18]$. Self-assessment is also a method for tracking performance progress that can be used to form necessary action plans to achieve increased performance, beginning with an evaluation of the current situation $[18,19]$.

Assessment against the EFQM's nine criteria is both beneficial and acknowledged as necessary for achieving excellence in managing operations. Organizations applying for an EQA need to provide evidence that they have met each of the criteria. However, the main purpose of self-assessment is to identify an organization's strengths and areas for improvement so action plans can be developed to improve organizational performance [19]. 
According to the EFQM scoring system, assessors give a score to each subcriterion through a comprehensive analysis of available information. The process mainly relies on the assessors' individual background, their experience in selfassessment, their interpretation of the EFQM criteria, and their individual perceptions of excellence. This, therefore, presents issues of consistency and accuracy [20].

The EFQM also includes some self-assessment approaches: a questionnaire, a matrix chart, a workshop, proformas, and an award simulation model [21]. Among these approaches, the questionnaire is the easiest way to perform self-assessment. However, it relies on a consensus process between the team members. Assessors and experts opting to hold face-to-face consensus meetings can choose from several different formats including brain-storming, nominal group techniques, etc. [16]. Moreno-Rodriguez et al. (2013) proposed a consensus support model based on linguistic information for self-assessment through questionnaires [22].

In response to criticisms of the EFQM model's selfmeasurement system, Li and Yang (2003) developed a more scientific and precise method of scoring. Their decision model focuses on the "processes" criterion, using an evidential reasoning approach as an MCDM technique to analyze the assessment data. They investigated the model's efficacy in two companies - an electricity company and a water supply company [20].

$\mathrm{Xu}$ and Yang (2003) conducted an investigation of the EFQM model in the UK where internal subject matter experts used the "Business Excellence Through Action" (BETA) approach to assess their organization [1]. BETA assessment fundamentally relies on MCDM techniques and is formulated through a software-based intelligent decision system, called IDS-BETA. The research results demonstrate that IDS-BETA is not only able to calculate average scores, but it is also able to derive numerical results and graphical comparisons of an organization's performance, strengths, and weaknesses [1, 23]. Moreover, the IDS-BETA package provides an organized knowledge base to assist assessors with impartial judgment, including: guidelines determined by the developers of the BETA approach; successful applications from award-winning organizations; evidence gathered from organizations undergoing evaluation; and justifications for prior assessor evaluations. Four small UK companies, the industry partners of the research project, have already implemented preliminary self-assessment using the IDS-BETA package [1, 23].

More research based on MCDM models can be found in the efforts of Ahmed et al. (2003) and Yang et al. (2001). Ahmed et al. (2003) introduced an eight-level structured framework for self-assessment to facilitate rapid and accurate scoring for organizations [12], while Yang et al. (2001) introduced an MCDM-based approach for self-assessing excellence that aids in decreasing subjectivity when scoring an organization's performance against the criteria in the EFQM model [24].

Moreover, several studies have incorporated the use of fuzzy sets in EFQM self-assessment. Mimi (2000) proposed a methodology based on fuzzy control systems that provides an efficient way of changing linguistic approximations into an automatic control strategy. The components of the EFQM model are interpreted as linguistic variables, and fuzzy intervals are used for their representation. A hierarchical structure is then used for the aggregation process [25]. More recently, researchers have made improvements to EFQM's assessment systems by combining fuzzy logic and MCDM techniques. For example, Aydin et al. (2012) proposed a new integrated approach based on a new fuzzy analytic hierarchy process to evaluate the business performance excellence [26]. Ezzabadi et al. (2015) developed an integrated approach that relies on a fuzzy analysis hierarchy technique and operations research models to improve the level of organizational excellence. The idea is to increase the quality of performance evaluation by identifying the highest priority improvement projects [9].

Table 1 summarizes the current self-assessment methods. As shown, most methods rely on MCDM techniques. Consequently, they are subjective and do not capture the interrelationships among the EFQM model's criteria. However, since the EFQM assessment is complex and contains some levels of uncertainty, several approaches incorporate procedures that assign weights to the performance criteria. However, these models are not able to accurately gauge the assessors' knowledge and experience with assessment or the assessment system.

Further, the relationships between EFQM criteria are often nonlinear, but in current assessment systems, these criteria are considered to have linear relationships.

TABLE I

CURRENT SELF-ASSESSMENT METHODS

\begin{tabular}{llll}
\hline Method & Basis theory & $\begin{array}{l}\text { Fuzzy } \\
\text { logic }\end{array}$ & Reference \\
\hline Mimi (2000) & Fuzzy control system & Yes & {$[25]$} \\
Yang et al. (2001) & MCDM & No & {$[24]$} \\
Li and Yang (2003) & MCDM & No & {$[20]$} \\
Xu and Yang (2003) & MCDM & No & {$[1]$} \\
Ahmed et al. (2003) & MCDM & No & {$[12]$} \\
Aydin et al. (2012) & MCDM & Yes & {$[26]$} \\
Rodriguez et al. (2013) & Consensus & Yes & {$[22]$} \\
Ezzabadi et al. (2015) & MCDM & Yes & {$[9]$} \\
\hline
\end{tabular}

\section{Fuzzy Sets and Numbers}

Zadeh was the first to introduce our modern conception of fuzzy logic to deal with uncertainty, vagueness, or imprecision in problems [27]. Fuzzy set theory, which is based on fuzzy logic, assigns a degree of membership to a particular object or a variable in a given set [27].

Definition 1 (Fuzzy set): Fuzzy set $A$ is defined in terms of a universal set $X$ by a membership function that assigns a value $\mu_{A}(x)$ in the interval $[0,1]$, i.e., $A: X \rightarrow[0,1]$ to each element $x \in X$ [27].

Definition 2 (Fuzzy number): A fuzzy set $A$ in $\mathbb{R}$ satisfies the following conditions [28]:

- $A$ is normal.

- $A_{\alpha}$ is a closed interval for every $\alpha \in(0,1]$.

- The support of $A$ is bounded.

Definition 3 (Linguistic variable): A linguistic variable is a variable whose values are words or sentences in a natural or artificial language [29]. A linguistic variable is characterized by the variables $X, T, U$, and $M$ where: 
- $X$ is the name of the linguistic variable (e.g., weather temperature).

- $T$ is the set of linguistic values that $\mathrm{X}$ can take (e.g., \{ cold, pleasant, hot $\}$ ).

- $U$ is the physical domain from which the linguistic variable $X$ takes its quantitative (crisp) values (e.g., $[-20$, $\left.40]{ }^{\circ} \mathrm{C}\right)$.

- $M$ is a semantic rule that relates each linguistic value in $T$ with a fuzzy set in $U$.

Definition 4 (FIS): An FIS has three parts: fuzzification, a fuzzy inference engine, and defuzzification. The fuzzification process forms the fuzzy sets for all input variables. The fuzzy inference engine uses fuzzy logic operations to generate an output by considering the logical relationships between the input variables. The defuzzification process converts the fuzzy output set into crisp values [30].

There are several inference methods; however, the most commonly used methods in the fuzzy community are Mamdani [31] and Takagi and Sugeno [32]. Table 2 lists the characteristics of Mamdani's model.

TABLE II

MAMDANI FUZZY MODEL [28]

\begin{tabular}{|c|c|c|}
\hline Operation & Operator & Formula \\
\hline Union (OR) & MAX & $\begin{array}{c}\mu_{C}(x)=\max \left(\mu_{A}(x), \mu_{B}(x)\right) \\
=\mu_{A}(x) \vee \mu_{B}(x)\end{array}$ \\
\hline Intersection (AND) & MIN & $\begin{array}{c}\mu_{C}(x)=\min \left(\mu_{A}(x), \mu_{B}(x)\right) \\
=\mu_{A}(x) \wedge \mu_{B}(x)\end{array}$ \\
\hline Implication & MIN & $\min \left(\mu_{A}(x), \mu_{B}(x)\right)$ \\
\hline Aggregation & MAX & $\max \left(\min \left(\mu_{A}(x), \mu_{B}(x)\right)\right)$ \\
\hline Defuzzification & CENTROID & $C O A=Z^{*}=\frac{\int z \mu_{C}(z) d z}{\int \mu_{C}(z) d z}$ \\
\hline
\end{tabular}

$\mu_{C}(x)=$ value of the resultant membership function

$\mu_{A}(x)=$ value of the membership function where the input belongs to the fuzzy set A

$\mathrm{z}=$ abscissa value, $\mu_{C}(z)$ is the ordinate

\section{THE FuZZY SELF-ASSESSMENT METHOD}

This section presents the new fuzzy self-assessment model. The model mainly relies on a network of FISs to incorporate assessor experience into the EFQM model. Figure 2 illustrates the modeling process including inputs, main processes, and outputs.

\section{A. Hierarchy of the EFQM model}

The EFQM model is subdivided into three levels: areas, criteria, and subcriteria as shown in Figure 3. The area level includes enablers and results. The criteria level includes leadership, people, policy and strategy, partnerships and resources, and the processes for enablers. This level also includes the results for the people, customer, society, and business dimensions. The subcriteria level includes 24 enabler criteria and eight results criteria as summarized in Table $3[3$, 5].

\section{B. Forming the Assessment Team}

A critical step in the self-assessment process is selecting an evaluation team. The excellence criteria are extensive, comprising human resource management and organizational behavior (leadership, people management, and people satisfaction results), business analysis, and process management. No individual is likely to have exhaustive knowledge of all areas, making it necessary to select an evaluation team from a wide cross-section of areas. A quality manager or systems engineer, with in-depth organizational knowledge, is generally selected as a lead assessor for internal self-assessments. This person usually holds an EFQM assessor certification. The lead assessor then selects additional company managers to join the team. These managers are trained in EFQM assessment and typically hold positions as human resource manager, production manager, or marketing manager. A similar process is followed for external assessments.

TABLE III

EFQM MODEL SUBCRITERIA LEVEL

\begin{tabular}{|c|c|}
\hline Criterion & Description \\
\hline $1 \mathrm{a}$ & $\begin{array}{l}\text { Leaders develop the mission, vision, values and ethics, and act } \\
\text { as role models. }\end{array}$ \\
\hline $1 b$ & $\begin{array}{l}\text { Leaders define, monitor, review, and drive the improvement of } \\
\text { the organization's management system and performance. }\end{array}$ \\
\hline $1 \mathrm{c}$ & Leaders engage with external stakeholders. \\
\hline $1 d$ & $\begin{array}{l}\text { Leaders reinforce a culture of excellence with the } \\
\text { organization's people. }\end{array}$ \\
\hline $1 \mathrm{e}$ & $\begin{array}{l}\text { Leaders ensure that the organization is flexible and manages } \\
\text { change effectively. }\end{array}$ \\
\hline $2 \mathrm{a}$ & $\begin{array}{l}\text { Strategy is based on understanding the needs and expectations } \\
\text { of both stakeholders and the external environment. }\end{array}$ \\
\hline $2 b$ & $\begin{array}{l}\text { Strategy is based on understanding internal performance and } \\
\text { capabilities. }\end{array}$ \\
\hline $2 \mathrm{c}$ & $\begin{array}{l}\text { Strategy and supporting policies are developed, reviewed, and } \\
\text { updated. }\end{array}$ \\
\hline $2 d$ & $\begin{array}{l}\text { Strategy and supporting policies are communicated, } \\
\text { implemented, and monitored. }\end{array}$ \\
\hline $3 \mathrm{a}$ & People plans support the organization's strategy. \\
\hline $3 b$ & People's knowledge and capabilities are developed. \\
\hline $3 \mathrm{c}$ & People are aligned, involved, and empowered. \\
\hline $3 \mathrm{~d}$ & People communicate effectively throughout the organization. \\
\hline $3 \mathrm{e}$ & People are rewarded, recognized, and cared for. \\
\hline $4 \mathrm{a}$ & Partners and suppliers are managed for sustainable benefit. \\
\hline $4 b$ & Finances are managed to secure sustained success. \\
\hline $4 \mathrm{c}$ & $\begin{array}{l}\text { Buildings, equipment, materials, and natural resources are } \\
\text { managed in a sustainable way. }\end{array}$ \\
\hline $4 d$ & Technology is managed to support the delivery of strategy. \\
\hline $4 \mathrm{e}$ & $\begin{array}{l}\text { Information and knowledge are managed to support effective } \\
\text { decision making and to build the organization's capability. }\end{array}$ \\
\hline $5 \mathrm{a}$ & $\begin{array}{l}\text { Processes are designed and managed to optimize stakeholder } \\
\text { value. }\end{array}$ \\
\hline $5 b$ & $\begin{array}{l}\text { Products and services are developed to create optimum value } \\
\text { for customers. }\end{array}$ \\
\hline $5 \mathrm{c}$ & Products and services are effectively promoted and marketed. \\
\hline $5 d$ & Products and services are produced, delivered and managed. \\
\hline $5 \mathrm{e}$ & Customer relationships are managed and enhanced. \\
\hline $\begin{array}{l}6 \mathrm{a}, 7 \mathrm{a} \\
8 \mathrm{a}, 9 \mathrm{a} \\
6 \mathrm{~b}, 7 \mathrm{~b} \\
8 \mathrm{~b}, 9 \mathrm{~b}\end{array}$ & $\begin{array}{l}\text { Perception measures are used to give a clear understanding of } \\
\text { the effectiveness, from the customers' perspective. } \\
\text { Performance indicators are used by the organization to } \\
\text { monitor, understand, predict and improve its performance. }\end{array}$ \\
\hline
\end{tabular}

C. Conducting the Assessment Using the EFQM Assessment Form

The EFQM model uses RADAR logic, which is a structured approach to questioning the performance of an organization. The assessment is recorded on a questionnaire (Appendix I) that contains the RADAR logic elements for the enablers and results subcriteria. The first part of the form includes the elements for assessing the enablers subcriteria as explained in Table IV. 
Accepted Manuscript by the Journal of IEEE Transaction on Fuzzy Systems

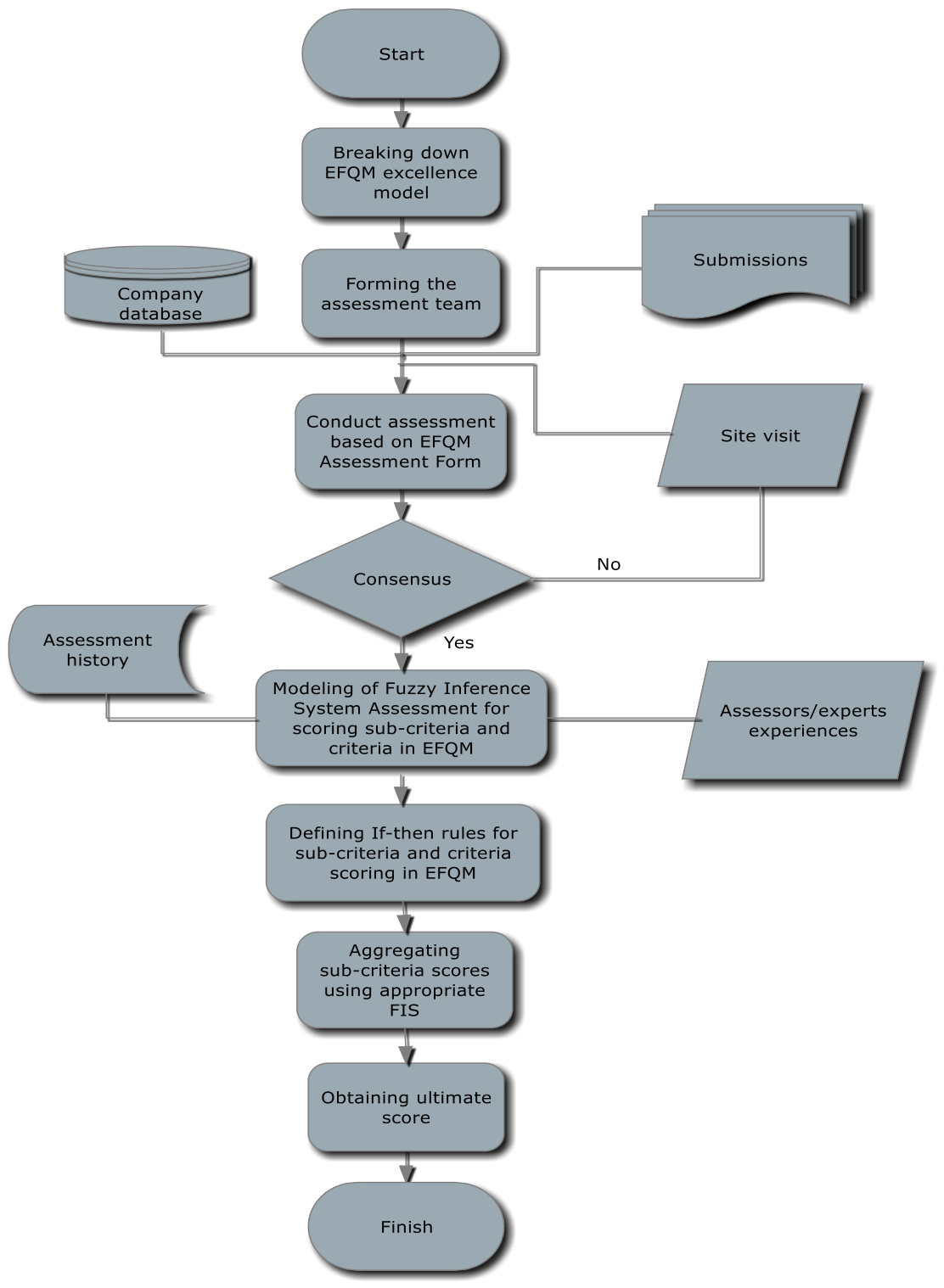

Fig. 2. The fuzzy self-assessment method.

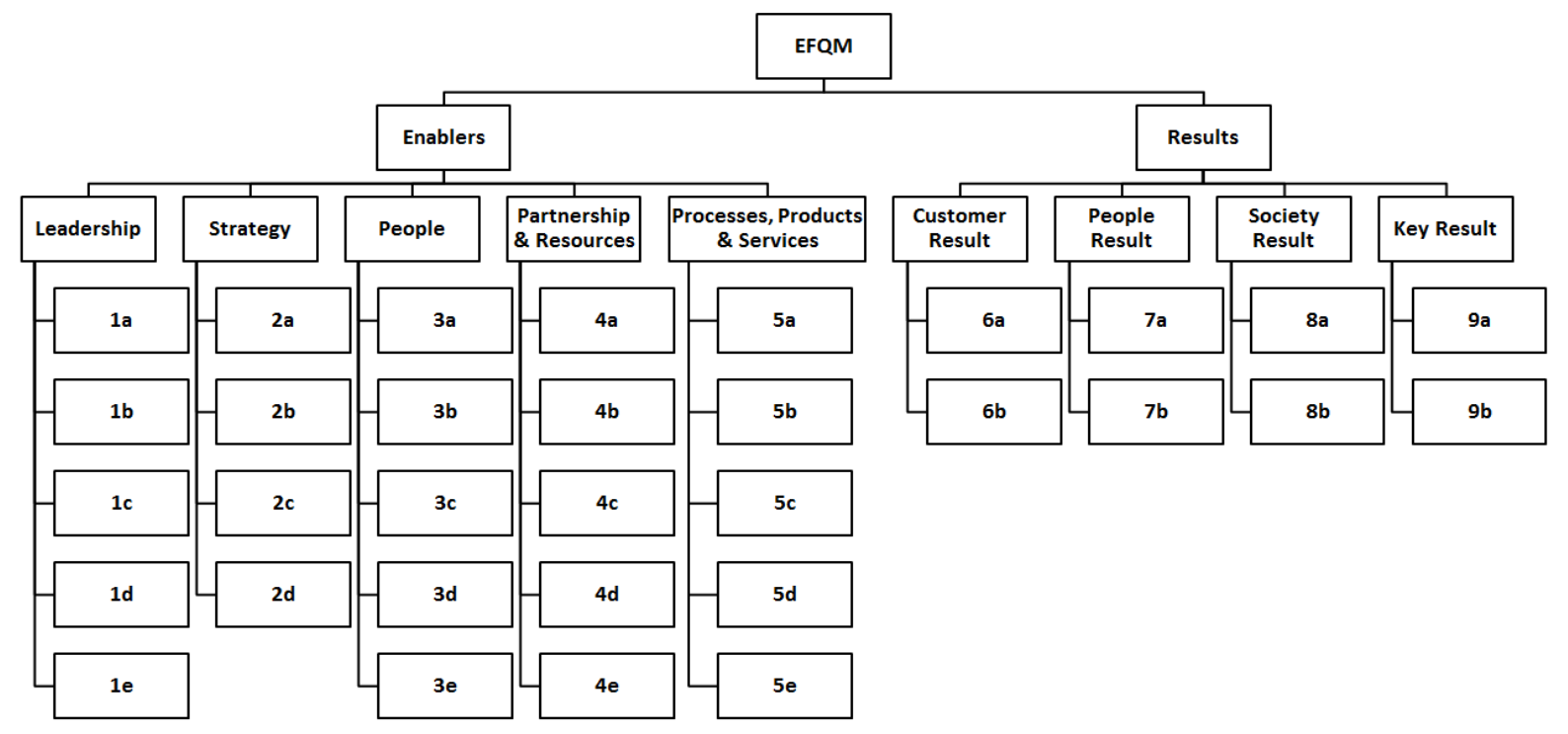

Fig. 3. The EFQM subdivisions. 
TABLE IV

RADAR LOGIC ELEMENTS FOR ASSESSING ENABLERS SUBCRITERIA

\begin{tabular}{ll}
\hline Criterion & Description \\
\hline Approach & $\begin{array}{l}\text { The approach is relevant and clear, and it supports the } \\
\text { other approaches. } \\
\text { The degree to which the approach is implemented. A } \\
\text { structured implementation plan exists. }\end{array}$ \\
$\begin{array}{l}\text { Assessment and } \\
\text { review }\end{array}$ & $\begin{array}{l}\text { Measures exist to assess the effectiveness of the } \\
\text { approach, and they are used to review and improve the } \\
\text { approach. } \\
\text { Result }\end{array}$ \\
The benefits are achieved, and the approach is \\
contributing to organizational goals. \\
Tmportance & $\begin{array}{l}\text { The difference between the present and the ideal } \\
\text { situation is being measured. } \\
\text { The weight of each subcriterion. }\end{array}$ \\
\hline
\end{tabular}

The second part of the form includes the elements for assessing the results subcriteria as presented in Table 5 .

TABLE V

RADAR LOGIC ELEMENTS FOR ASSESSING RESULTS SUBCRITERIA

\begin{tabular}{|c|c|}
\hline Criterion & Description \\
\hline Trends & $\begin{array}{l}\text { Trends are positive and/or there is sustained good } \\
\text { performance (at least three years). }\end{array}$ \\
\hline Targets & Targets have been set and achieved. \\
\hline Comparisons & $\begin{array}{l}\text { A comparison between current results and external } \\
\text { organizations exists. }\end{array}$ \\
\hline Causes & $\begin{array}{l}\text { The key approaches that drive results have been } \\
\text { determined. }\end{array}$ \\
\hline Gaps & $\begin{array}{l}\text { The difference between the present situation and the } \\
\text { ideal situation are being measured. }\end{array}$ \\
\hline Importance & The weight of each subcriterion. \\
\hline
\end{tabular}

\section{Consensus}

After individual assessment and scoring, the assessment team members exchange views on the submissions and reach consensus on the strengths, areas for improvement, site-visit issues, and scores. Considering the broad assessor-to-assessor variations that would normally be predictable, a sound consensus process is necessary. Additionally, the selfassessment process is more than merely a means of arriving at an average agreed score. It provides a learning opportunity for the assessors and enables the team to review and re-evaluate all the information and evidence resulting from the individual assessments to reach an agreement.

\section{E. Network Modeling of FISs}

Scoring is a crucial part of the assessment, and the current methods have inadequacies. These could be interpreted as a problem of the function approximations, which require a network to map the input space to the output space. As shown in Figure 4, a hybrid network of FISs is used to map the input space to the output space. The EFQM model is therefore subdivided into four network layers: subcriteria, criteria, areas, and the final score. Each network layer has its own FISs, which includes an input and an output space and its own if-then rules. Consequently, the final score is calculated using 44 FISs.

\section{1) Network Layer 3 - The Subcriteria Layer}

There are 32 FISs in the subcriteria layer, and each subcriterion has its own FIS. The input space comprises 12 variables: six variables for the enablers (approach, deployment, assessment and review, result, gaps, and importance) and six variables for the results (trends, targets, comparisons, causes,

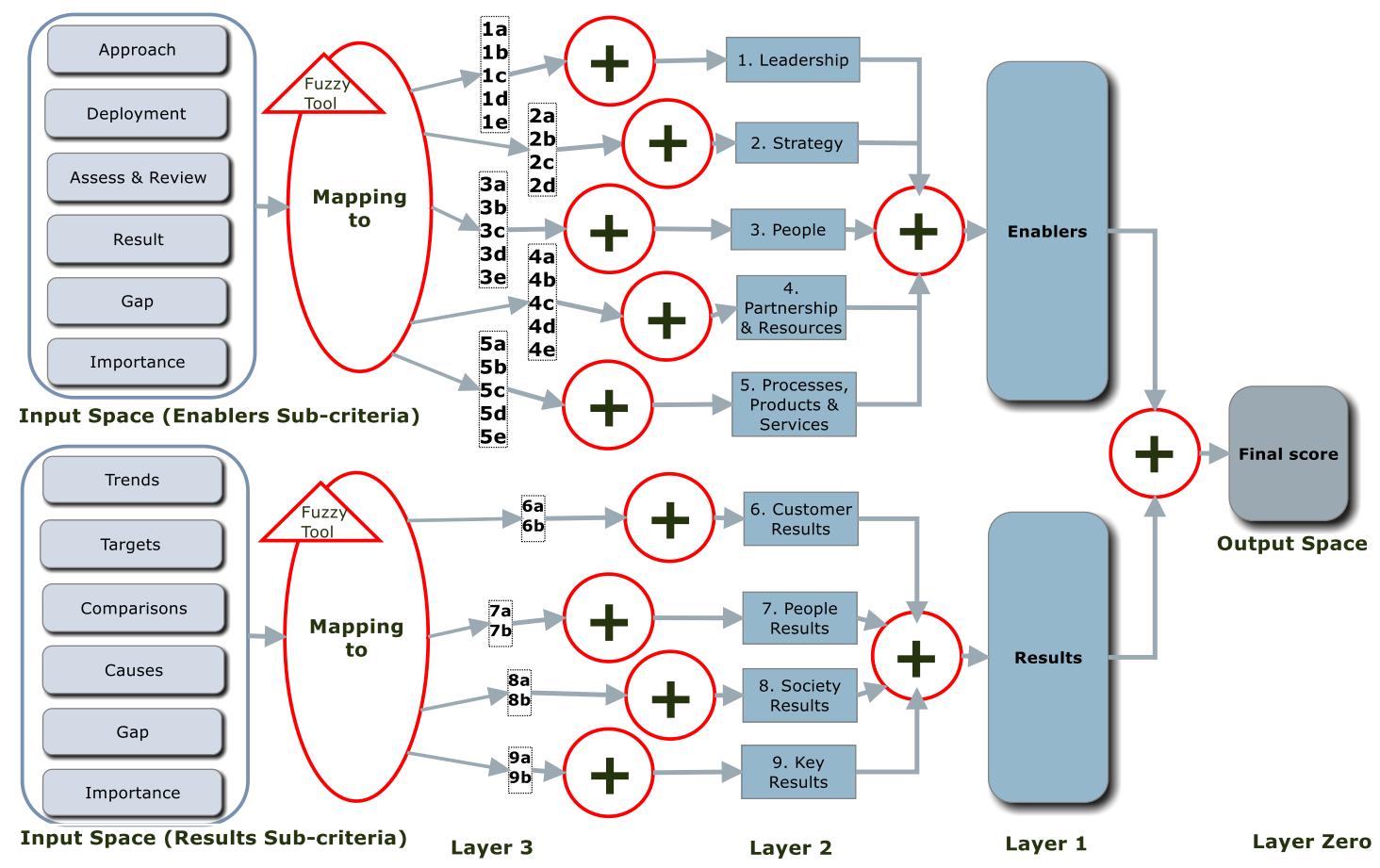

Fig. 4. Hierarchical fuzzy model for assessment in the EFQM model. 
gaps, and importance). The output space holds the scores for each subcriteria (i.e., 1a, 1b, etc.).

The initial fuzzy rules and membership functions are determined according to expert evaluations. Nominal group techniques and the EFQM assessment form are used to determine the assessors' views on the impacts the input variables should have on the output space. For example, a rule for calculating 1a score has the following structure:

"If Approach is Very High and Deployment is High and A \& $R$ is Medium and Results is High and Importance is Medium and Gap is Low then la score is High."

The scores for the 32 subcriteria form the output for Layer 3.

\section{2) Network Layer 2 - Criteria Layer}

The FISs in Layer 2 take the 32 scores (i.e., 1a, 1b, 1c, etc.) from the output space of Layer 3 as inputs. In this layer, there are nine criteria each with its own FIS. The modeling structure in this layer is similar to Layer 3. The input space for each criterion has a direct impact on the related criterion based on the EFQM model. For instance, the leadership criteria input space includes 1a, 1b, 1c, 1d, and 1e and for other criteria as illustrated in Figure 4. The FISs in this layer are Mamdani-type FISs, similar to Layer 3, and, again, the fuzzy rules are based on assessor evaluations. For example, after the aggregation process, the rule for the leadership criterion is structured as:

"If $1 a$ is Low and $1 b$ is Medium and $1 c$ is Medium and $1 d$ is Very Low and le is Low then leadership is Low."

Scores for each of the nine criteria (i.e., leadership, strategy, etc.) are then calculated.

\section{3) Network Layer 1-Area}

The area-level layer requires additional interim FISs to map the criteria outputs from network Layer 2 as inputs to either the enablers and results. The structure of this layer is similar to the previous layers. The input space for the enablers includes leadership, strategy, people, partnership and resources, and processes. The input space for the results area contains products and services. The FISs for this layer are also Mamdani-type, similar to Layer 2. After aggregating the assessor evaluations, a leadership rule for the enablers area might be expressed as follows:

"If leadership is High and strategy is High and people is Medium and partnership \& resources is Medium and processes, products \& services is Low then leadership is Medium".

The output space of layer 2 is the input space for Layer 1.

\section{4) Network Layer O - Final Score}

The final score is calculated by taking the output of Layer 1 as the input for Layer 0. Hence, another FIS maps the enablers and the result to the final score module to produce the end result. An example rule follows:

"If enablers is High and results is Medium then Final score is Medium".

\section{F. The Simulated Model}

A simulation model is developed using Matlab [33] as presented in Appendix II.

\section{APPLICATION}

Alliance International has played a crucial role in implementing quality management systems using the EFQM model, as well as other frameworks. The company brings extensive experience in organizational assessment and improvement in the service and manufacturing industries and the necessary discipline to achieve its business objectives. In addition, the company's lead assessors have significant industry experience in implementing state-of-the-art practices and as quality management professionals while working with various companies nationally and internationally. The proposed model was implemented in the Middle East Branch of Alliance International. A case was selected for validation from among the branch's current consulting projects that is relevant to the implementation and assessment of the EFQM model.

The assessment team comprised a lead assessor, two assessors, and an expert panel consisting of the managing director, the marketing and sales director, the engineering director, the logistics director, and the production director. The assessors are sufficiently experienced, well-trained, and qualified to assess the company.

\section{A. Membership Functions}

In this case, bell-shaped membership functions are used as variables. In most cases, these functions are capable of solving deep, complex problems with satisfactory results [34]. The input space for all variables is partitioned by five membership functions representing the following linguistic variables: Very Low (VL), Low (L), Medium (M), High (H), and Very High $(\mathrm{VH})$, as shown in Figure 5. The corresponding membership functions are represented based on the following equation:

$$
\mu_{A}(x)=\frac{1}{1+d(x-c)^{2}}
$$

where $x \in[0,1]$ is the element of universe $U, c$ indicates the standard score for determining verbal (linguistic) value of the input variables, and $d$ determines the shape of the membership function, which is 0.2 here.

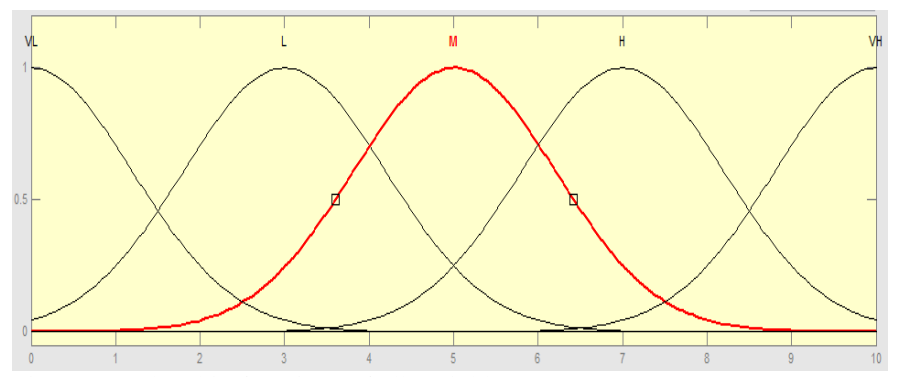

Fig. 5. Membership functions of all variables.

\section{B. The Assessment Process}

The external assessors and internal experts conducted their assessments using the EFQM assessment form, partially presented in Appendix I. After reaching a consensus, a final score was determined for each subcriterion based on the input variables. Table 6 shows the case study assessment for Layer 3, which includes the enablers subcriteria. Table 7 shows the scores for the results subcriteria. 
TABLE VI

CASE STUdy ASSESSMENT LAYER 3 - ENABLERS SUBCRITERIA

\begin{tabular}{|c|c|c|c|c|c|c|c|c|}
\hline z & 莺 & & 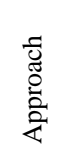 & 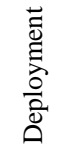 & 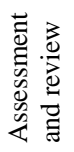 & $\begin{array}{l}\vec{Z} \\
\vec{\Xi} \\
\stackrel{0}{0}\end{array}$ & 芯 & 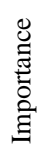 \\
\hline \multirow[t]{5}{*}{1} & \multirow[t]{5}{*}{ Leadership } & $1 \mathrm{a}$ & 5 & 3 & 3 & 3.5 & 6 & 4 \\
\hline & & $1 b$ & 3 & 4 & 3 & 3.75 & 7 & 3 \\
\hline & & $1 \mathrm{c}$ & 6 & 3.5 & 3.75 & 4 & 4 & 4 \\
\hline & & $1 d$ & 4 & 2.75 & 2 & 1.75 & 8 & 5 \\
\hline & & $1 \mathrm{e}$ & 6 & 3 & 2 & 2.75 & 5 & 6 \\
\hline \multirow[t]{5}{*}{2} & \multirow[t]{5}{*}{ Strategy } & $2 \mathrm{a}$ & 4.5 & 3.75 & 3.5 & 3.25 & 5.5 & 5 \\
\hline & & $2 b$ & 5.5 & 4.5 & 2.75 & 2.5 & 6 & 5 \\
\hline & & $2 \mathrm{c}$ & 3.75 & 2.75 & 2.25 & 2 & 7 & 5 \\
\hline & & $2 d$ & 3.5 & 3 & 3.5 & 3 & 6.5 & 5 \\
\hline & & $3 a$ & 3.5 & 2.5 & 1.75 & 1.5 & 6.25 & 5 \\
\hline \multirow[t]{4}{*}{3} & \multirow[t]{4}{*}{ People } & $3 b$ & 3.75 & 3.25 & 3 & 2.75 & 6.75 & 6 \\
\hline & & $3 \mathrm{c}$ & 3 & 2.25 & 2 & 1.5 & 7 & 7 \\
\hline & & $3 d$ & 4 & 3.25 & 2.75 & 2 & 6.25 & 5 \\
\hline & & $3 e$ & 4.5 & 3 & 2.5 & 1.75 & 5 & 6 \\
\hline \multirow[t]{5}{*}{4} & \multirow{5}{*}{$\begin{array}{l}\text { Partnerships } \\
\text { and resources }\end{array}$} & $4 a$ & 2.25 & 1.5 & 1 & 0.5 & 8 & 6 \\
\hline & & $4 b$ & 2.75 & 2 & 1.75 & 1.5 & 7.5 & 6 \\
\hline & & $4 \mathrm{c}$ & 1.75 & 1 & 0.75 & 0.5 & 8 & 4 \\
\hline & & $4 d$ & 3.5 & 2.75 & 2 & 1.5 & 6.5 & 5 \\
\hline & & $4 \mathrm{e}$ & 4 & 3 & 2.5 & 2 & 6 & 6 \\
\hline \multirow[t]{5}{*}{5} & \multirow{5}{*}{$\begin{array}{l}\text { Process, } \\
\text { products, and } \\
\text { services }\end{array}$} & $5 a$ & 4.75 & 3.5 & 3 & 2.75 & 5.5 & 7 \\
\hline & & $5 b$ & 3 & 2 & 1.5 & 1 & 7 & 8 \\
\hline & & $5 c$ & 5.5 & 4 & 3.75 & 3 & 5 & 6 \\
\hline & & $5 \mathrm{~d}$ & 4.5 & 3.5 & 3 & 2 & 5 & 6 \\
\hline & & $5 \mathrm{e}$ & 5 & 3 & 2 & 2 & 5 & 7 \\
\hline
\end{tabular}

TABLE VII

CASE StUdy AsSESSMENT LAYER 3 - RESUlts SubCRITERIA

\begin{tabular}{|c|c|c|c|c|c|c|c|c|}
\hline z & 莺 & 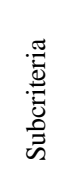 & 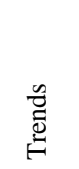 & 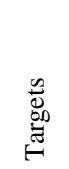 & 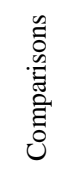 & $\begin{array}{l}\mathscr{y} \\
\text { 地 } \\
\tilde{E} \\
\tilde{U}\end{array}$ & 苞 & 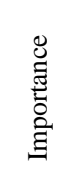 \\
\hline \multirow{2}{*}{6} & \multirow{2}{*}{ Customers results } & $6 a$ & 4 & 3.5 & 2.5 & 2 & 6 & 7 \\
\hline & & $6 b$ & 3.5 & 4 & 3.5 & 3 & 5 & 3 \\
\hline \multirow{2}{*}{7} & \multirow{2}{*}{ People results } & $7 \mathrm{a}$ & 3.75 & 3 & 2.25 & 2.5 & 6.5 & 7 \\
\hline & & $7 \mathrm{~b}$ & 4 & 3.25 & 2.5 & 2.5 & 6 & 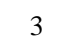 \\
\hline \multirow{2}{*}{8} & \multirow{2}{*}{ Community results } & $8 \mathrm{a}$ & 2.5 & 2 & 1.75 & 1.5 & 7.5 & 5 \\
\hline & & $8 b$ & 2.5 & 2.5 & 2 & 1.75 & 7.5 & 5 \\
\hline \multirow[b]{2}{*}{9} & \multirow{2}{*}{ Key results } & $9 a$ & 4 & 3.75 & 4 & 3.5 & 5.5 & . \\
\hline & & $9 b$ & 4.25 & 4 & 4.25 & 3.75 & 6 & 5 \\
\hline
\end{tabular}

The final scores for the subcriteria (Tables 8 and 9) were calculated by mapping the input space to the output space.
TABLE VIII

SCORES FOR LAYER 3 - ENABLERS SUBCRITERIA

\begin{tabular}{|c|c|c|c|c|}
\hline No & Criteria & & Subcriteria and short description & Score \\
\hline \multirow[t]{5}{*}{1} & \multirow[t]{5}{*}{ Leadership } & $1 \mathrm{a}$ & Vision, mission, and values & 8.8 \\
\hline & & $1 b$ & Management activities and performance & 8.04 \\
\hline & & $1 \mathrm{c}$ & Engagement with external stakeholders & 7.8 \\
\hline & & $1 d$ & Fostering teamwork & 6.62 \\
\hline & & $1 \mathrm{e}$ & Management of change & 6.33 \\
\hline \multirow[t]{4}{*}{2} & \multirow[t]{4}{*}{ Strategy } & $2 \mathrm{a}$ & $\begin{array}{l}\text { Stakeholders and the external environment } \\
\text { needs anticipation }\end{array}$ & 9.33 \\
\hline & & $2 b$ & $\begin{array}{l}\text { Internal performance and capabilities } \\
\text { (the unique strengths of the organization) }\end{array}$ & 9.01 \\
\hline & & $2 \mathrm{c}$ & $\begin{array}{l}\text { Strategy development, implementation, and } \\
\text { monitoring }\end{array}$ & 8.25 \\
\hline & & $2 d$ & Strategy communication and deployment & 9.37 \\
\hline \multirow[t]{5}{*}{3} & \multirow[t]{5}{*}{ People } & $3 a$ & Human resources plan & 6.13 \\
\hline & & $3 b$ & People's capabilities & 6.39 \\
\hline & & $3 \mathrm{c}$ & Empowerment & 6.22 \\
\hline & & $3 d$ & Communication & 6.36 \\
\hline & & $3 e$ & Reward and recognition & 6.78 \\
\hline \multirow[t]{5}{*}{4} & \multirow{5}{*}{$\begin{array}{l}\text { Partnerships } \\
\text { and } \\
\text { resources }\end{array}$} & $4 a$ & Partnerships & 5.82 \\
\hline & & $4 \mathrm{~b}$ & Technological support for processes & 5.94 \\
\hline & & $4 \mathrm{c}$ & Sustainability & 5.09 \\
\hline & & $4 d$ & Technology & 6.1 \\
\hline & & $4 \mathrm{e}$ & Knowledge sharing & 6.32 \\
\hline \multirow[t]{5}{*}{5} & \multirow{5}{*}{$\begin{array}{l}\text { Process, } \\
\text { products, } \\
\text { and services }\end{array}$} & $5 \mathrm{a}$ & $\begin{array}{l}\text { Management and improvement of key } \\
\text { processes }\end{array}$ & 7.69 \\
\hline & & $5 b$ & Innovation & 6.3 \\
\hline & & $5 \mathrm{c}$ & Marketing and promotion & 7.73 \\
\hline & & $5 \mathrm{~d}$ & Production/delivery/service & 6.71 \\
\hline & & $5 \mathrm{e}$ & Relationship management & 6.63 \\
\hline
\end{tabular}

TABLE IX

SCORES FOR LAYER 3 - RESULTS SUBCRITERIA

\begin{tabular}{llllc}
\hline No & Criteria & \multicolumn{2}{l}{ Subcriteria and short description } & Score \\
\hline 6 & Customer results & $6 \mathrm{a}$ & Perceptions measures & 50.1 \\
& & $6 \mathrm{~b}$ & Performance indicators & 15.2 \\
7 & People results & $7 \mathrm{a}$ & Perceptions measures & 33.4 \\
& & $7 \mathrm{~b}$ & Performance indicators & 33.4 \\
\multirow{2}{*}{8} & \multirow{2}{*}{ Community results } & $8 \mathrm{a}$ & Perceptions measures & 16.1 \\
& & $8 \mathrm{~b}$ & Performance indicators & 18 \\
9 & \multirow{2}{*}{ Key results } & $9 \mathrm{a}$ & Perceptions measures & 33.2 \\
& & $9 \mathrm{~b}$ & Performance indicators & 33.8 \\
\hline
\end{tabular}

TABLE X

SCORES FOR LAYER 2 - ENABLERS CRITERIA

\begin{tabular}{llccccccc}
\hline No Criteria & \multicolumn{5}{c}{ Input } & Score \\
\hline 1 & Leadership & $1 \mathrm{a}$ & $1 \mathrm{~b}$ & $1 \mathrm{c}$ & $1 \mathrm{~d}$ & $1 \mathrm{e}$ & 38.3 \\
& & 8.8 & 8.04 & 7.8 & 6.62 & 6.33 & \\
2 & Strategy & $2 \mathrm{a}$ & $2 \mathrm{~b}$ & $2 \mathrm{c}$ & $2 \mathrm{~d}$ & & \\
& & 9.33 & 9.01 & 8.25 & 9.37 & & 37.5 \\
3 & People & $3 \mathrm{a}$ & $3 \mathrm{~b}$ & $3 \mathrm{c}$ & $3 \mathrm{~d}$ & $3 \mathrm{e}$ & \\
& & 6.13 & 6.39 & 6.22 & 6.36 & 6.78 & 35.9 \\
4 & Partnerships and resources & $4 \mathrm{a}$ & $4 \mathrm{~b}$ & $4 \mathrm{c}$ & $4 \mathrm{~d}$ & $4 \mathrm{e}$ & \\
& 5.82 & 5.94 & 5.09 & 6.1 & 6.32 & 33
\end{tabular}

5 Process, products, and services $5 \mathrm{a} \quad 5 \mathrm{~b} \quad 5 \mathrm{c} \quad 5 \mathrm{~d} \quad 5 \mathrm{e}$

63.9 
The outputs of Layer 3 are the inputs for Layer 2. Table 10 shows the inputs and outputs for Layer 2, Enablers criteria, and Table 11 shows the inputs and outputs for Layer 2 - the results criteria.

TABLE XI SCORES FOR LAYER 2 - RESULTS CRITERIA

\begin{tabular}{llccc}
\hline No & Criteria & \multicolumn{2}{c}{ Input } & Score \\
\hline 6 & Customer results & $6 \mathrm{a}$ & $6 \mathrm{~b}$ & 64.3 \\
& & 50.1 & 15.2 & \\
7 & People results & $7 \mathrm{a}$ & $7 \mathrm{~b}$ & 68.9 \\
& & 33.4 & 33.4 & \\
8 & \multirow{2}{*}{ Community results } & $8 \mathrm{a}$ & $8 \mathrm{~b}$ & 36.7 \\
& & 16.1 & 18 & \\
9 & \multirow{2}{*}{ Key results } & $9 \mathrm{a}$ & $9 \mathrm{~b}$ & 66.9 \\
& & 33.2 & 33.8 & \\
\hline
\end{tabular}

Table 12 shows the inputs and outputs for Layer 1 - both the enablers and results areas.

TABLE XII

SCORES FOR LAYER 1 - ENABLERS AND RESULTS AREAS

\begin{tabular}{|c|c|c|c|c|c|c|c|}
\hline No & Area & & & Input & & & Score \\
\hline \multirow[t]{2}{*}{1} & Enablers & Leadership & Strategy & Staff & Partnersh & rocesses & \multirow{2}{*}{274} \\
\hline & & 38.3 & 37.5 & 35.9 & 33 & 63.9 & \\
\hline 2 & Results & $\begin{array}{c}\text { Customer } \\
64.3\end{array}$ & $\begin{array}{c}\text { People } \\
68.9\end{array}$ & $\begin{array}{c}\text { Community } \\
36.7\end{array}$ & $\begin{array}{l}\text { Key } \\
66.9\end{array}$ & & 256 \\
\hline
\end{tabular}

In Layer 0, there is one FIS that maps the enablers and results areas as inputs to generate a final score for the EFQM model as the output. Table 13 shows the inputs and outputs for Layer 0.

TABLE XIII

SCORES FOR LAYER 0 - FINAL SCORE

\begin{tabular}{|c|c|c|c|c|}
\hline No & EFQM & \multicolumn{2}{|c|}{ Input } & Score \\
\hline \multirow{2}{*}{1} & \multirow{2}{*}{ Final score } & Enablers & Results & \multirow{2}{*}{513} \\
\hline & & 274 & 256 & \\
\hline
\end{tabular}

\section{DISCUSSION}

In general sense, the validity of the model is based on its performance and case-by-case investigations. These results were discussed with and assured by the relevant senior managers, company experts, and qualified assessors. In this particular case, there were notable differences between the traditional approach and the proposed model.

Table 14, for example, shows the results for the leadership subcriteria. The values in the classical approach column are based on a simple questionnaire in keeping with the EFQM model. According to the EFQM model, after forming the assessment team, each assessor collects the relevant information according to RADAR logic and the EFQM model. Subsequent to the individual assessment and scoring, the assessment team members assemble to exchange their views on the submission and achieve consensus on the strengths, areas for improvement, site-visit issues, and scores. They then agree on a score, that is essentially an average of the score for each EFQM criteria and subcriteria and record those scores on a summary sheet. See, for example, the score for 1a (10) in Table 14. The values in the new method column are based on the fuzzy multi-layer assessment method presented in Section III. The assessors provide their evaluations for each subcriteria with respect to RADAR logic using linguistic variables. Then, the simulated model that underpins the FISs embedded into each layer calculate the scores automatically, i.e., 8.8 for 1a in Table 14.

TABLE XIV

COMPARISON OF FUZZY AND CLASSICAL ASSESSMENT SYSTEMS

\begin{tabular}{|c|c|c|c|c|}
\hline No & Criteria & Subcriteria & Classical approach & New method \\
\hline \multirow[t]{5}{*}{1} & \multirow[t]{5}{*}{ Leadership } & $1 \mathrm{a}$ & 10 & 8.8 \\
\hline & & $1 b$ & 8 & 8.04 \\
\hline & & $1 \mathrm{c}$ & 12 & 7.8 \\
\hline & & $1 d$ & 5 & 6.62 \\
\hline & & $1 \mathrm{e}$ & 3 & 6.33 \\
\hline \multirow[t]{4}{*}{2} & \multirow[t]{4}{*}{ Strategy } & $2 \mathrm{a}$ & 14 & 9.33 \\
\hline & & $2 b$ & 10 & 9.01 \\
\hline & & $2 \mathrm{c}$ & 9 & 8.25 \\
\hline & & $2 d$ & 15 & 9.37 \\
\hline \multirow[t]{5}{*}{3} & \multirow[t]{5}{*}{ People } & $3 a$ & 9 & 6.13 \\
\hline & & $3 b$ & 10 & 6.39 \\
\hline & & $3 \mathrm{c}$ & 7 & 6.22 \\
\hline & & $3 d$ & 9 & 6.36 \\
\hline & & $3 e$ & 5 & 6.78 \\
\hline \multirow[t]{5}{*}{4} & \multirow{5}{*}{$\begin{array}{l}\text { Partnerships } \\
\text { and resources }\end{array}$} & $4 a$ & 7 & 5.82 \\
\hline & & $4 b$ & 9 & 5.94 \\
\hline & & $4 \mathrm{c}$ & 8 & 5.09 \\
\hline & & $4 d$ & 6 & 6.1 \\
\hline & & $4 \mathrm{e}$ & 7 & 6.32 \\
\hline \multirow[t]{5}{*}{5} & \multirow{5}{*}{$\begin{array}{l}\text { Process, } \\
\text { products, and } \\
\text { services }\end{array}$} & $5 \mathrm{a}$ & 12 & 7.69 \\
\hline & & $5 b$ & 5 & 6.3 \\
\hline & & $5 c$ & 6 & 7.73 \\
\hline & & $5 \mathrm{~d}$ & 9 & 6.71 \\
\hline & & $5 e$ & 8 & 6.63 \\
\hline
\end{tabular}

As can be seen, in many rows the scores of the classical approach and new method are different considerably. From the experts' perspective, the scores provided by the proposed model are more reasonable and reliable. For example, the score for $1 \mathrm{c}$ subcriteria in the leadership criteria is 12 calculated by the classical method whereas it is 7.8 obtained from the proposed method which is more realistic for the case under investigation, or the classical score for the 1e is very low for the case study in compare with the new method score.

The efficiency of the classic approach to EFQM assessment cannot be improved by considering the available data or expert knowledge. This is why, in real-world applications, decision makers and assessors are not generally satisfied with its results. Moreover, the knowledge and experience of the expert panels and assessors that is prescribed in the EFQM model is often inherently vague and uncertain.

Theoretically, the proposed fuzzy method makes decision making easier by means of linguistic terms and approximate reasoning. It captures the judgments of specialists and stores 
them in a knowledge base to minimize rough evaluations that lead to suboptimal measurements. It can handle both quantitative data and imprecisely defined qualitative information.

Further, the proposed fuzzy method can be extended in practical terms for use with any number of inputs, whereas expanding classical models is challenging. Moreover, this method provides more informative and reliable analytical results and facilitates assessment and decision making for managers, experts, and assessors in far less time. The model can facilitate systematic, continuous quality improvement and provides a means for managers to develop improvement plans.

In comparison with current MCDM-based assessment methods, the proposed model overcome several challenges:

1) Existing MCDM-based methods either focus on obtaining the final result as a ranking or a utility function to aid decision makers. They typically overlook the relationships among the involved criteria and fail to identify the imprecise reasoning embedded in their criteria with respect to the addressed problem.

2) These MCDM-based methods assume that the criteria are independent and hierarchical in structure. However, the relationships among criteria in EFQM model are usually interdependent with certain feedback effects. To identify the interrelated relationships among variables, the DEMATEL technique can build an influential network relations matrix to find the influential weights of DEMATEL-based ANP (DANP) [35]. This technique can model some, but not all, of the interdependent and feedback relationships among criteria.

3) In MCDM-based methods like FANP, the interdependence among the factors must be analyzed first to reduce the number of pairwise comparisons, which is one of its most often-mentioned disadvantages [35]. Considering the number of criteria and subcriteria in the EFQM model, such models are not efficient.

4) The traditional multi-attribute utility models might not indicate the real system behaviors [35]. Instead, the fuzzy method can aggregate the values of multiple attributes in a nonadditive approach. The mathematical modeling of non-additive aggregation can correct some of the problematic assumptions found in traditional additive-type models, such as linear independence.

Despite its benefits, the proposed method has some limitations. It relies solely on fuzzy rules elicited from experts. Further, tuning the fuzzy rules through machine learning could improve the performance of this method with historical data, which may be addressed in future work.

\section{CONCLUSION AND FUTURE WORKS}

Self-assessment using the EFQM Business Excellence model provides a framework for sustained and continuous organizational improvement. The self-assessment process is a comprehensive, systematic, and regular review that allows organizations to clearly discern their strengths and areas for improvement. The process culminates in planned actions for improvement, which are monitored for progress. The qualitative nature of many of the decision situations that characterize the assessment of excellence, and the experts that dispense those judgments, lends itself to the application of fuzzy logic and fuzzy linguistic variables. Therefore, this paper presents a new fuzzy hierarchal self-assessment method based on FISs that relies on fuzzy linguistic variables. The proposed method has been applied in a real-world case study and has been compared to traditional approaches.

To promote this area of research and further development of intelligent assessment systems, future studies might aim to develop models that can integrate expert knowledge with the historical behavior of variables using machine learning techniques. In addition, the performance of the proposed approach needs to be investigated through more real-world case studies.

\section{APPENDIX I}

Part of the questionnaire is provided here.

\begin{tabular}{|c|c|c|c|c|c|c|c|}
\hline \multicolumn{2}{|r|}{ Criterion 1: LEADERSHIP } & 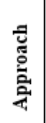 & 泀 & 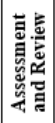 & 壱 & हैं & 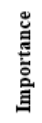 \\
\hline \multicolumn{8}{|c|}{$\begin{array}{l}\text { Definition: } \\
\text { Excellent organizations have leaders who shape the future and make it happen, acting as role models } \\
\text { for its values and ethics and inspiring trust at. all times. They are flexible, enabling the organization to } \\
\text { anticipate and react in a timely manner to ensure the ongoing success of the organization. } \\
\text { This section explores the activities and behaviours of the leadership (please defined who the leaders are } \\
\text { taken into consideration here). For each of the questions below, agree one score for the statements } \\
\text { described against Approach, Deployment, Assessment and Review, Results, Gap and Importance. }\end{array}$} \\
\hline \multicolumn{8}{|c|}{$\begin{array}{l}\text { Please assign a linguistic variable for each question based on RADAR logic: } \\
\text { Very Low }(V L) \text {, Low }(L) \text {, Medium }(M) \text {, High }(H) \text {, and Very High (VH) }\end{array}$} \\
\hline \multirow[t]{2}{*}{ la } & Vision, mission and values & & & & & & \\
\hline & $\begin{array}{l}\text { Leaders develop the mission, vision, values and ethics and } \\
\text { act as role models. }\end{array}$ & & & & & & \\
\hline \multirow[t]{2}{*}{ lb } & Management activities and performance & & & & & & \\
\hline & $\begin{array}{l}\text { Leaders define, monitor, review and drive the } \\
\text { improvement of the organization's management system } \\
\text { and performance. }\end{array}$ & & & & & & \\
\hline \multirow[t]{2}{*}{ lc } & Engagement with external stakeholders & & & & & & \\
\hline & $\begin{array}{l}\text { Leaders engage with customers, partners and } \\
\text { representatives of society. }\end{array}$ & & & & & & \\
\hline \multirow[t]{2}{*}{ ld } & Fostering teamwork & & & & & & \\
\hline & $\begin{array}{l}\text { Leaders reinforce a culture of excellence with the } \\
\text { organization's people. }\end{array}$ & & & & & & \\
\hline \multirow[t]{2}{*}{ le } & Management of change & & & & & & \\
\hline & $\begin{array}{l}\text { Leaders ensure that the organization is flexible and } \\
\text { manages change effectively. }\end{array}$ & & & & & & \\
\hline \multicolumn{2}{|c|}{ Comments: (Strengths and AFIs) } & & & & & & \\
\hline \multicolumn{2}{|c|}{ Form completed by: } & & & & & & \\
\hline
\end{tabular}

\section{APPENDIX II}

Figure below presents a block diagram of the simulated model developed by Matlab. The color-coding for the Layer 3 output scores follows: blue - leadership subcriteria; pink strategy subcriteria; gold - people subcriteria; orange partnerships and resources subcriteria; red - processes, products, and services subcriteria; and yellow - customers, people, society and results subcriteria. Green, purple, dark green, and dark red represent Mux blocks that combine specific criteria inputs with the output scores in various layers. Green denotes the enabler criteria inputs. Purple denotes the result criteria inputs. Dark green denotes the enabler and results criteria inputs for Layer 1. Lastly, dark red denotes the combined enabler and results criteria inputs for the final score calculation in Layer 0. 


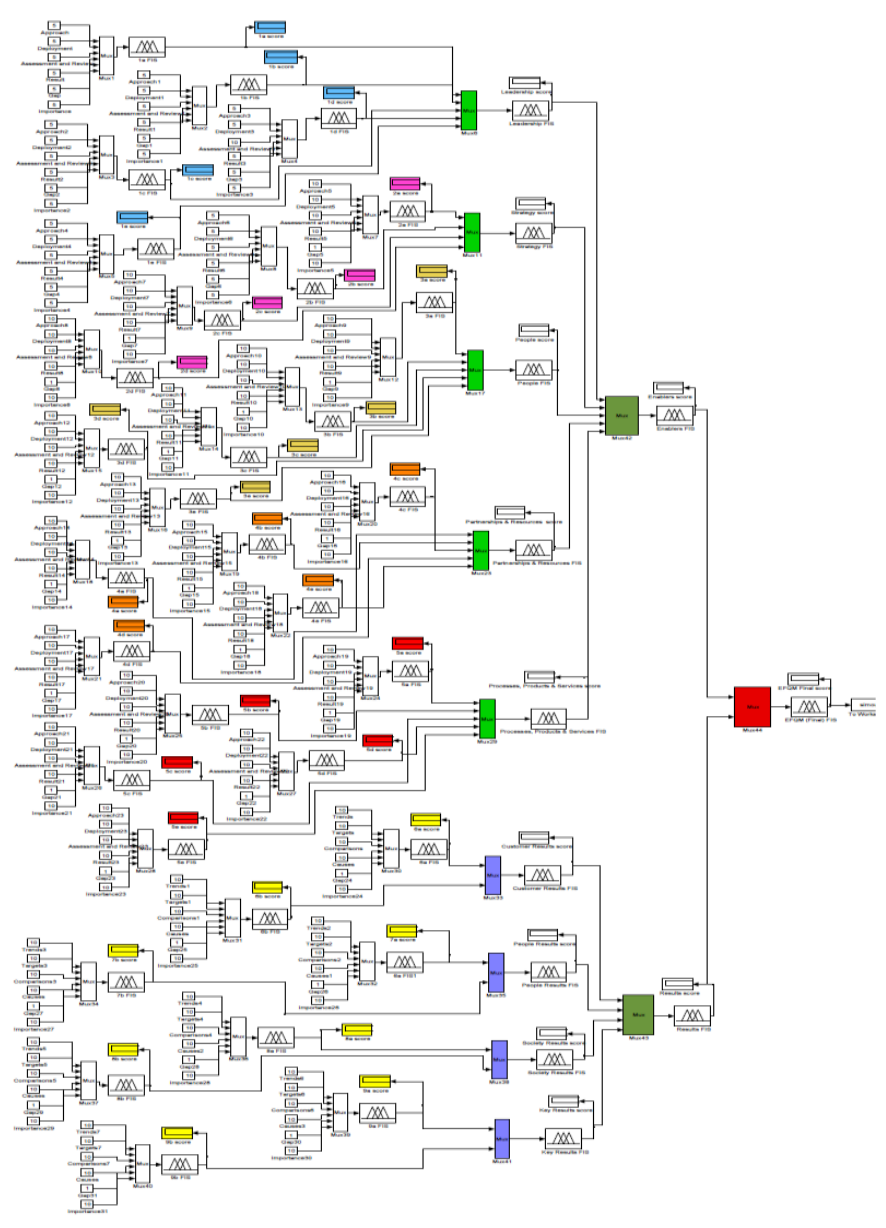

\section{REFERENCES}

[1] D.-L. Xu, and J.-B. Yang, "Intelligent decision system for selfassessment," Journal of Multi-Criteria Decision Analysis, vol. 12, no. 1, pp. 43-60, January/February 2003, 2003.

[2] EFQM. "The Fundamental Concepts of Excellence," 20 December 2009; www.efqm.org/uploads.

[3] EFQM. "Introducing Excellence," 15 September 2008; www.efqm.org/uploads.

[4] S. Vernero, U. Nabitz, G. Bragonzi et al., "A two-level EFQM selfassessment in an Italian hospital," International Journal of Health Care Quality Assurance, vol. 20, no. 3, pp. 215-231, 2007.

[5] EFQM. "Introducing the EFQM Excellence Model 2010," 15 November 2010; www.efqm.org.

[6] A. Calvo-Mora, A. Leal, and J. L. Roldan, "Using enablers of the EFQM model to manage institutions of higher education," Quality Assurance in Education, vol. 14, no. 2, pp. 99-129, 2006.

[7] G. Antunes, A. Pires, and V. MacHado, "Ecomomics aspects of quality and organizational performance - A study in Setbal care homes for elderly persons," Total Quality Management and Business Excellence, vol. 19, no. 1-2, pp. 79-88, 2008.

[8] J. J. Tari, and S. De Juana-Espinosa, "EFQM model self-assessment using a questionnaire approach in university administrative services," TQM Magazine, vol. 19, no. 6, pp. 604-616, 2007.

[9] J. Hosseini Ezzabadi, M. Dehghani Saryazdi, and A. Mostafaeipour, "Implementing Fuzzy Logic and AHP into the EFQM model for performance improvement: A case study," Applied Soft Computing Journal, vol. 36, pp. 165-176, 2015.

[10] A. E. Ziaei, H. Alirezaee, A. Riyahi et al., "Assess causal relationships of EFQM model criteria using fuzzy dematel (case study: Tovseeh Taavon bank)," International Business Management, vol. 10, no. 11, pp. 2185-2189, 2016.

[11] Y. L. Liu, and P. F. Ko, "A modified EFQM Excellence Model for effective evaluation in the hotel industry," Total Quality Management and Business Excellence, pp. 1-14, 2017.
[12] A. M. Ahmed, J. B. Yang, and B. G. Dale, "Self-Assessment Methodology: The Route to Business Excellence," The Quality Management Journal, vol. 10, no. 1, pp. 15, 2003.

[13] M. A. Sajedi, R. M. Yusuff, A. L. Majid Zerafat et al., "An improved TOPSIS/EFQM methodology for evaluating the performance of organizations," Life Science Journal, vol. 10, no. 1, pp. 4315-4322, 2013.

[14] EFQM, The EFQM Excellence Model, Brussels: Public and Voluntary Sectors, EFQM, 1999a.

[15] G. Kanji, Measuring business excellence: Psychology Press, 2002.

[16] L. J. Porter, S. J. Tanner, and E. European Centre for Business, Assessing business excellence : a guide to business excellence and selfassessment, Amsterdam [Netherlands]; Boston, Mass.: Elsevier, 2004.

[17] K. W. Gadd, "Business Self Assessment, A Strategic Tool for Building Process Robustness and Achieving Integrated Management," Business Process Re-engineering and Management Journal, vol. 1, no. 3, pp. 20, 1995.

[18] J. Sturkenboom, T. Van Der Wiele, and A. Brown, "An action-oriented approach to quality management self-assessment in small and mediumsized enterprises," Total Quality Management, vol. 12, no. 2, pp. 231246, 2001.

[19] EFQM, Assessing for Excellence. A Practical Guide for SelfAssessment, Brussels: The European Foundation for Quality Management, 1999b.

[20] M. Li, and J. Yang, "A decision model for self-assessment of business process based on the EFQM excellence model," International Journal of Quality \& Reliability Management, vol. 20, no. 2, pp. 164-188, 2003.

[21] J. Daniel, R. M. Yusuff, and J. Jassbi, “Assessment System Based on Fuzzy Scoring In European Foundation for Quality Management (EFQM): Business Excellence Model," African Journal of Business Management, vol. 5, no. 15, pp. 6209-6220, 2011.

[22] J. Moreno-Rodrı, F. J. Cabrerizo, I. J. Pérez et al., “A consensus support model based on linguistic information for the initial-self assessment of the EFQM in health care organizations," Expert Systems with Applications, vol. 40, no. 8, pp. 2792-2798, 2013.

[23] D.-L. Xu, McCarthy, and J.-B. Yang, "Intelligent decision system and its application in business innovation self assessment," Decision Support Systems, vol. 42, no. 2, pp. 664-673, 2006.

[24] J. B. Yang, B. G. Dale, and C. H. R. Siow, "Self-assessment of excellence: an application of the evidential reasoning approach," International Journal of Production Research, vol. 39, no. 16, pp. 3789-3812, 2001.

[25] F. Mimi, "Self-assessment procedure using fuzzy sets," in Intelligent Systems in Design and Manufacturing III, 2000, pp. 432-440.

[26] S. Aydin, C. Kahraman, and İ. Kaya, "A new fuzzy multicriteria decision making approach: An application for European Quality Award assessment," Knowledge-Based Systems, vol. 32, pp. 37-46, 2012.

[27] L. A. Zadeh, "Fuzzy sets," Information and Control, vol. 8, no. 3, pp. 338-353, 1965.

[28] M. Naderpour, J. Lu, and G. Zhang, "An intelligent situation awareness support system for safety-critical environments," Decision Support Systems, vol. 59, pp. 325-340, 2014.

[29] L. A. Zadeh, "The concept of a linguistic variable and its application to approximate reasoning-I," Information Sciences, vol. 8, no. 3, pp. 199-249, //, 1975.

[30] A. S. Markowski, M. S. Mannan, A. Kotynia et al., "Application of fuzzy logic to explosion risk assessment," Journal of Loss Prevention in the Process Industries, vol. 24, no. 6, pp. 780-790, 2011.

[31] E. H. Mamdani, "Application of fuzzy logic to approximate reasoning using linguistic synthesis," IEEE Transactions on Computers, vol. C26, no. 12, pp. 1182-1191, 1977.

[32] S. Nazir, S. Colombo, and D. Manca, "Testing and analyzing different training methods for industrial operators: an experimental approach," Computer Aided Chemical Engineering, K. Andrzej and T. Ilkka, eds., pp. 667-672: Elsevier, 2013.

[33] MathWorks., "The MATLAB user's guides," I. The MathWorks, ed., 2012.

[34] A. S. Markowski, and M. S. Mannan, "Fuzzy risk matrix," Journal of hazardous materials, vol. 159, no. 1, pp. 152-157, 2008.

[35] G.-H. Tzeng, and K.-Y. Shen, New concepts and trends of hybrid multiple criteria decision making: CRC Press, 2017. 